\title{
Early detection of contractile dysfunction in GRMD dogs by post-processing of standard cine FLASH-MRI
}

Raymond Gilles ${ }^{1 *}$, Jean-Laurent Thibaud ${ }^{2}$, Marcel Toussaint ${ }^{3}$, Stéphane Blot ${ }^{2}$, Pierre G Carlier ${ }^{4}$

From 2011 SCMR/Euro CMR Joint Scientific Sessions

Nice, France. 3-6 February 2011

\section{Introduction}

Duchenne muscular dystrophy (DMD) due to dystrophin deficiency leads to death by heart failure in nearly $30 \%$ of cases. An early detection of myocardial abnormalities in these patients would help in the optimization of their management. The GRMD is a canine model of DMD, that develops a severe cardiomyopathy.

\section{Purpose}

Post-processing of standard cine-MR images of young GRMD dogs, before any sign of cardiac global dysfunction is patent. The aim of the study was to detect minor changes in synchronism or contraction patterns of the left ventricle of golden retriever muscular dystrophy (GRMD) dog as compared to control dogs.

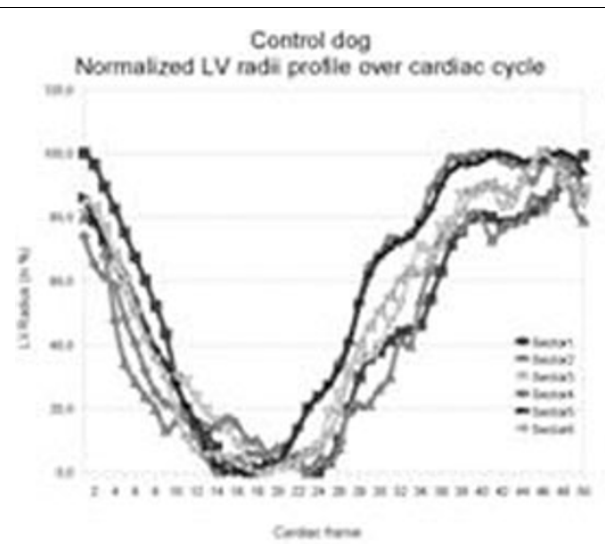

\section{GRMO dog}

Normaszed LV rade proste over carsiac cycle

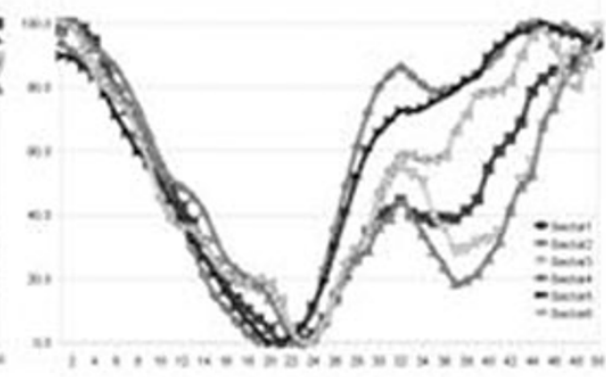

cantors
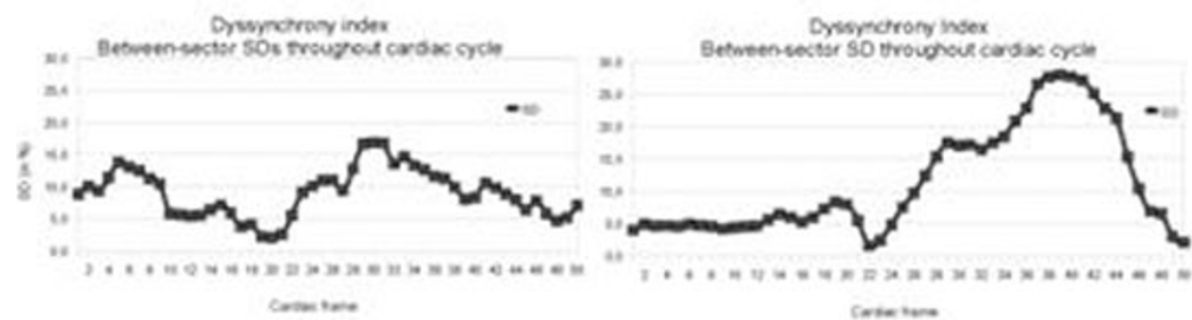

Figure 1 Upper panel: Examples of basal slice radius curves in a control dog (left) and a GRMD (right) throughout cardiac cycle. Lower panel: corresponding time-courses of dyssynchrony index.

${ }^{1}$ CHWAPI, Tournai, Belgium

Full list of author information is available at the end of the article 


\section{Methods}

6-month old GRMD $(n=5)$ and control dogs $(n=4)$ were imaged using a Siemens Magnetom Trio TIM with a standard cine-FLASH sequence in short axis. Acquisition parameters were as follows: TE:3.06ms, TR:19.74ms, flip angle: $15^{\circ}$, slice thickness: $6 \mathrm{~mm}$, in plane resolution:1.8x1.8mm ${ }^{2}$, NEX:3, GRAPPA:2. Each dog heart was covered by 8 slices. We used the Segment ${ }^{\circledast}$ software to define the endo- and epicardial contours and analyze radii and wall thicknesses in each slice with a 6 segment model. The radii and wall thickness curves were smoothed using a Savitzky-Golay filter. For each slice, a dyssynchrony index was calculated, as the SD of the normalized radii across the six segments throughout the cardiac cycle. Max dRadius/dt and max dWT/dt were also extracted for each segment of each slice.

\section{Results}

HR, LVEF, peak ejection rate and SV were not statistically different between GRMDs and controls. EDV was somewhat smaller in GRMDs $(46.0 \pm 8.4$ vs $34.7 \pm 5.2 \mathrm{ml}$; $\mathrm{p}=0.04)$. The GRMDs showed an higher mean dyssynchrony index of the 4 most basal slices lower than the controls (11.5 \pm 1.9 vs $9.7 \pm 2.3 \%$; $\mathrm{p}=0.015)$. Max dRadius/dt during contraction and during relaxation was higher in GRMDs than in controls ( $58 \pm 21$ vs $37 \pm 12 \mathrm{~mm} / \mathrm{s} ; \mathrm{p}<0.001$ ) and $(63 \pm 25$ vs $46 \pm 16 \mathrm{~mm} / \mathrm{s} ; \mathrm{p}<0.001)$. The same appeared true for $\max \mathrm{dWT} / \mathrm{dt}$ in contraction and relaxation $(33 \pm 16$ vs $116 \pm 109 \mathrm{~mm} / \mathrm{s} ; \mathrm{p}<0.001$ and $43 \pm 20$ vs $119 \pm 132$ $\mathrm{mm} / \mathrm{s} ; \mathrm{p}<0.001$ for controls vs GRMDs). Figure 1.

\section{Conclusions}

Pre-clinical contractile abnormalities can be detected by post-hoc analysis of standard cine MR images in GRMD dogs. This preliminary results should encourage further work on early detection of myocardial minimal dysfunction in GRMD dogs but also in DMD and Becker muscular dystrophy patients.

\section{Author details}

${ }^{1} \mathrm{CHWAPI}$, Tournai, Belgium. ²Ecole Nationale Vétérinaire d'Alfort, Alfort, France. ${ }^{3} \mathrm{CH}$ Sud Francilien, Corbeil-Essonnes, France. ${ }^{4}$ Institut Myologie / Pitié-Salpétrière and CEA, Paris, France.

Published: 2 February 2011

doi:10.1186/1532-429X-13-S1-P337

Cite this article as: Gilles et al:: Early detection of contractile dysfunction in GRMD dogs by post-processing of standard cine FLASH-MRI. Journal of Cardiovascular Magnetic Resonance 2011 13(Suppl 1):P337.
Submit your next manuscript to BioMed Central and take full advantage of:

- Convenient online submission

- Thorough peer review

- No space constraints or color figure charges

- Immediate publication on acceptance

- Inclusion in PubMed, CAS, Scopus and Google Scholar

- Research which is freely available for redistribution

Submit your manuscript at www.biomedcentral.com/submit 